\title{
Mitochondrial Function and Diabetes: Consequences for Skeletal and Cardiac Muscle Metabolism
}

Citation for published version (APA):

Schrauwen-Hinderling, V. B., Kooi, E., \& Schrauwen, P. (2016). Mitochondrial Function and Diabetes: Consequences for Skeletal and Cardiac Muscle Metabolism. Antioxidants \& Redox Signaling, 24(1), 3951. https://doi.org/10.1089/ars.2015.6291

Document status and date:

Published: 01/01/2016

DOI:

10.1089/ars.2015.6291

Document Version:

Publisher's PDF, also known as Version of record

Document license:

Taverne

Please check the document version of this publication:

- A submitted manuscript is the version of the article upon submission and before peer-review. There can be important differences between the submitted version and the official published version of record.

People interested in the research are advised to contact the author for the final version of the publication, or visit the DOI to the publisher's website.

- The final author version and the galley proof are versions of the publication after peer review.

- The final published version features the final layout of the paper including the volume, issue and page numbers.

Link to publication

\footnotetext{
General rights rights.

- You may freely distribute the URL identifying the publication in the public portal. please follow below link for the End User Agreement:

www.umlib.nl/taverne-license

Take down policy

If you believe that this document breaches copyright please contact us at:

repository@maastrichtuniversity.nl

providing details and we will investigate your claim.
}

Copyright and moral rights for the publications made accessible in the public portal are retained by the authors and/or other copyright owners and it is a condition of accessing publications that users recognise and abide by the legal requirements associated with these

- Users may download and print one copy of any publication from the public portal for the purpose of private study or research.

- You may not further distribute the material or use it for any profit-making activity or commercial gain

If the publication is distributed under the terms of Article $25 \mathrm{fa}$ of the Dutch Copyright Act, indicated by the "Taverne" license above, 


\title{
Mitochondrial Function and Diabetes: Consequences for Skeletal and Cardiac Muscle Metabolism
}

\author{
Vera B. Schrauwen-Hinderling, ${ }^{1-3}$ Marianne Eline Kooi, ${ }^{1,3,4}$ and Patrick Schrauwen ${ }^{2,3}$
}

\begin{abstract}
Significance: An early hallmark in the development of type 2 diabetes is the resistance to the effect of insulin in skeletal muscle and in the heart. Since mitochondrial function was found to be diminished in patients with type 2 diabetes, it was suggested that this defect might be involved in the etiology of insulin resistance. Although several hypotheses were suggested, yet unclear is the mechanistic link between these two phenomena. Recent Advances: Herein, we review the evidence for disturbances in mitochondrial function in skeletal muscle and the heart in the diabetic state. Also the mechanisms involved in improving mitochondrial function are considered and, whenever possible, human data is cited. Critical Issues: Reported evidence shows that interventions that improve skeletal muscle mitochondrial function also improve insulin sensitivity in humans. In the heart, available data from animal studies suggests that enhancement of mitochondrial function can reverse aging-induced changes in heart function, and can be protective against cardiomyopathy and heart failure. Future Directions: Mitochondria and their functions can be targeted with the aim of improving skeletal muscle insulin sensitivity and cardiac function. However, human clinical intervention studies are needed to fully substantiate the potential of mitochondria as a target to prevent cardiometabolic disease. Antioxid. Redox Signal. 24, 39-51.
\end{abstract}

\section{Mitochondria: Their Role in the Prevention and Treatment of Type 2 Diabetes Mellitus}

$\mathbf{T}$ YPe 2 Diabetes mellitus is a chronic disease that is characterized by insulin resistance and elevated plasma glucose concentrations. During the postprandial phase, skeletal muscle is the major site of glucose uptake and a reduced insulin-stimulated glucose uptake into the muscle is suggested to play an important role in the development of whole body insulin resistance and type 2 diabetes. At a molecular level, skeletal muscle insulin resistance has been shown to be initiated by interference of fatty acid intermediates with insulin signaling $(17,38,68)$, resulting in a reduced translocation of glucose transporter 4 (GLUT4) to the muscle cell membrane. In this respect, a reduced fat oxidative capacity and, more recently, a reduced overall mitochondrial metabolism have been postulated to underlie the develop- ment of lipid-induced insulin resistance. In fact, mitochondrial dysfunction was suggested to be involved in the etiology of insulin resistance and type 2 diabetes (58). A decline in mitochondrial function has also been suggested to occur in the heart of type 2 diabetic patients, underlying certain forms of cardiomyopathy and heart failure $(12,65)$. Indeed, type 2 diabetic patients have a two-fold increased risk of developing heart failure, irrespective of hypertension and cardiovascular disease (21).

Most human data on the role of mitochondrial function in type 2 diabetes are available from the skeletal muscle. This organ can be easily accessible for obtaining biopsies, enabling ex vivo tissue analysis of mitochondrial metabolism. For cardiac muscle, this is more difficult and advances in this field strongly depend on noninvasive methodology. As an exception, recent clinical studies examined cardiac tissue that was sampled during heart surgery and examined ex vivo for

Departments of ${ }^{1}$ Radiology and ${ }^{2}$ Human Biology, ${ }^{3}$ NUTRIM School for Nutrition, Toxicology and Metabolism, and ${ }^{4}$ CARIM School for Cardiovascular Diseases in Maastricht, Maastricht University Medical Center, Maastricht, The Netherlands. 
mitochondrial respiration $(3,67,73)$. Currently, our knowledge about human cardiac mitochondrial metabolism is expanding rapidly. Here, we will review the role of mitochondrial function in the muscle and heart, with an emphasis on human data.

\section{Mitochondrial dysfunction in skeletal muscle}

In the past decade of the previous century, it became recognized that type 2 diabetic patients are characterized by a reduced fat oxidative capacity. Early on in the present century, interest turned toward skeletal muscle mitochondria when a coordinated reduction of a large cluster of oxidative genes (OXPHOS) was reported in the skeletal muscle of patients with type 2 diabetes; a diminished expression of the coordinating transcription factor peroxisome proliferator coactivator $1-\alpha$ (PGC-1 $\alpha)$ was also reported $(64,69,78)$. Interestingly, these changes in mitochondrial markers were already visible in healthy subjects who were at an increased risk of developing diabetes, pointing out mitochondrial dysfunction as an early event in the development of diabetes.

In subsequent years, mitochondrial function in type 2 diabetic patients and healthy subjects was investigated with a wide range of methodologies, identifying aberrations in various aspects of appearance and performance of mitochondria in diabetes, which will be described next. Some (87, $92,101)$, but not all studies (20) that used in vivo phosphorus magnetic resonance spectroscopy $\left({ }^{31} \mathrm{P}-\mathrm{MRS}\right)$ identified phosphocreatine $(\mathrm{PCr})$ recovery after exercise to be delayed, suggesting a decreased in vivo mitochondrial capacity in type 2 diabetic patients. In these experiments, the time course of $\mathrm{PCr}$ is monitored by ${ }^{31} \mathrm{P}-\mathrm{MRS}$ in vivo, while subjects perform an exercise protocol inside the MR scanner. During exercise, $\mathrm{PCr}$ is consumed in skeletal muscle to form the adenosine triphosphate (ATP) needed for contraction. After cessation of exercise, $\mathrm{PCr}$ concentrations are quickly restored to resting values.
Using ${ }^{31} \mathrm{P}-\mathrm{MRS}$ methodology, the recovery of $\mathrm{PCr}$ can be examined in detail (Fig. 1). It was shown earlier that the resynthesis of $\mathrm{PCr}$ is almost exclusively fueled by aerobic metabolism (83) and therefore, the rate constant (or half-time) of PCr recovery can be used as an index of mitochondrial capacity (46). Indeed, parameters of PCr kinetics correlate with ex vivo markers of mitochondrial function and whole body oxygen uptake $\left(\mathrm{VO}_{2 \max }\right)(52,97)$.

Alternative ${ }^{31} \mathrm{P}-\mathrm{MRS}$ methods using saturation transfer methods examined ATP synthesis rates in muscle at rest and found decreased ATP synthesis rates in diabetic and prediabetic subjects, which was interpreted as hampered mitochondrial function (80). However, one should be aware that in this experimental setting, resting ATP synthesis is assessed, which is different from the investigation of maximal capacity of mitochondria (usually referred to as mitochondrial "function"). Saturation transfer data are even more difficult to interpret as not only oxidative but also especially glycolytic (nonmitochondrial) metabolism is examined by this method. As a result, the saturation transfer method overestimates the ATP synthesis rate many fold (45). Notwithstanding the limitations of saturation transfer methods, $\mathrm{PCr}$ recovery data correlated with ATP saturation transfer data, indicating that differences in unidirectional ATP synthesis rate as determined by saturation transfer may still give some indication of mitochondrial impairment (88).

Apart from noninvasive in vivo methodologies, an ex vivo analysis of mitochondrial respiration in muscle biopsies has been performed. In fresh muscle biopsies, oxygen consumption can be monitored in permeabilized muscle fibers or isolated mitochondria by high-resolution respirometry, via measurement of oxygen consumption on adenosine diphosphate (ADP) addition and substrates for oxidation. Using this methodology, basal as well as maximal ADP-stimulated respiration was reported to be decreased in type 2 diabetic patients $(66,82)$, and it persisted even after correction for mitochondrial density.

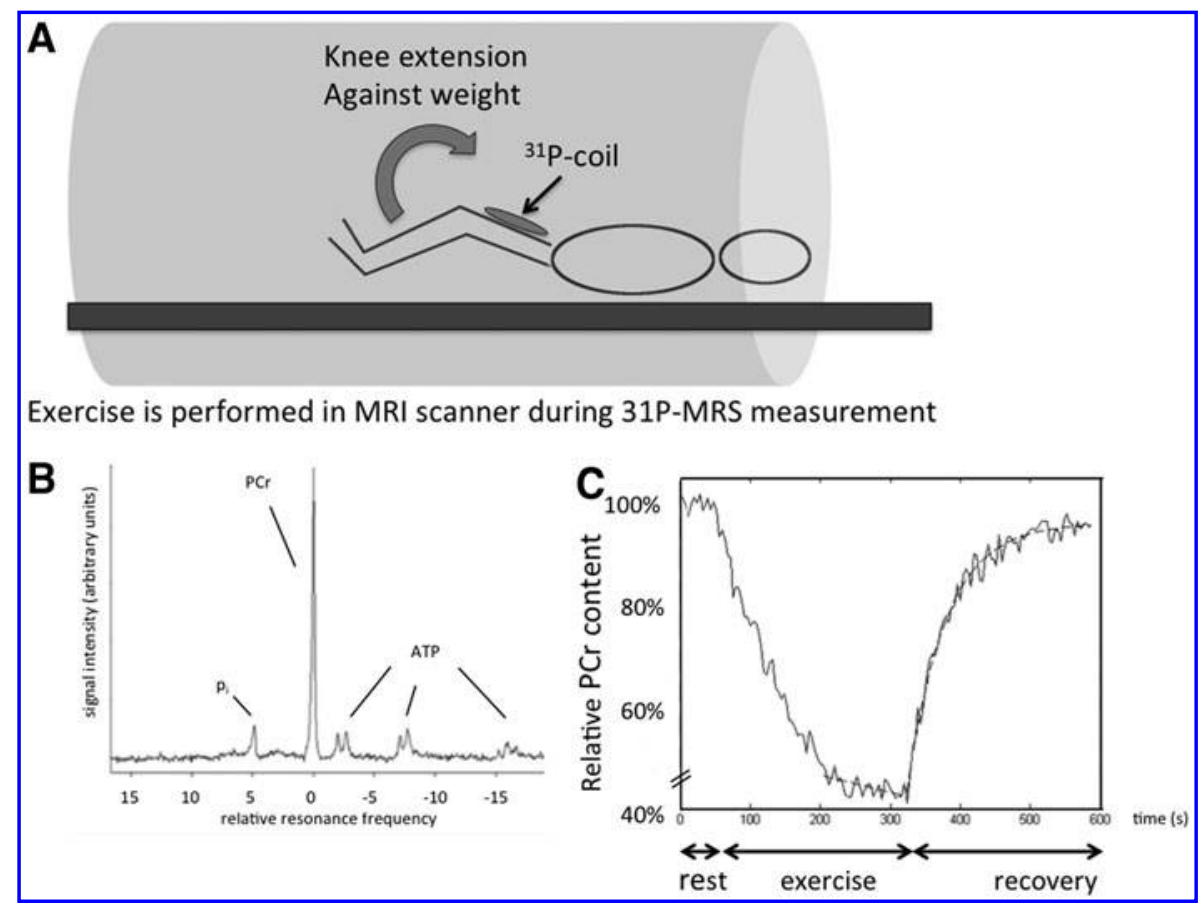

FIG. 1. Determination of $\mathrm{PCr}$ kinetics by ${ }^{31} \mathrm{P}$-MRS. (A) A patient is monitored with an MRI scanner and ${ }^{31} \mathrm{P}-\mathrm{MRS}$ while performing exercise; $\mathrm{PCr}$ kinetics is recorded in the active muscle. (B) ${ }^{A}{ }^{31} \mathrm{P}$ spectrum of the vastus lateralis muscle. The resonance of inorganic phosphate (pi), $\mathrm{PCr}$, and ATP is depicted. (C) Time course of $\mathrm{PCr}$ during exercise and recovery of a patient with type 2 diabetes (male, age $=67$ years, BMI $=31 \mathrm{~kg}$ / $\mathrm{m}^{2}$ ). Spectra were measured every $4 \mathrm{~s}$. A mono-exponential curve can be fitted to the curve of recovery of $\mathrm{PCr}$ after exercise to determine the half-time or rate constant. ATP, adenosine triphosphate; BMI, body mass index; MRS, magnetic resonance spectroscopy; $\mathrm{PCr}$, phosphocreatine. 
In addition to functional measurements, small mitochondria with altered morphology were reported in skeletal muscle of type 2 diabetic patients $(27,44)$ when investigated by electron microscopy, suggesting increased mitochondrial damage in diabetes. In search for explanatory mechanisms, increased levels of reactive oxygen species (ROS) were reported in skeletal muscle from type 2 diabetic subjects (4, 35). ROS may damage various organelles, including mitochondria. Hyperglycemia is known to increase ROS production (for review, see Ref. 28); therefore, hyperglycemia, inherent to diabetes, may also play a role in increasing mitochondrial ROS concentrations in vivo. Furthermore, damaged mitochondria, in turn, are known to produce higher levels of ROS (70), leading to a vicious cycle of mitochondrial damage (Fig. 2). In addition, the smaller and damaged mitochondria may also be a reflection of the impaired mechanisms of mitochondrial quality control (6).

Our knowledge about mitochondrial dynamics is currently rapidly increasing and processes involving mitochondrial fusion, fission, and mitophagy are investigated in detail (26a, $50 \mathrm{a}, 72,86)$. It is suggested that along with age and metabolic disease, the cycle of mitochondrial fusion and fission is disturbed, resulting in a less stringent quality control, which decreases the ATP-generating capacity of mitochondria (reviewed in Ref. 60). Hallmark conditions of obesity and type 2 diabetes such as hyperglycemia and hyperlipidemia stimulate processes of mitochondrial fission in cell culture (103), resulting in fragmentation of the mitochondrial network, thereby hampering fusion-fission dynamics. In line with this, Mitofusin2 (Mfn2) was found to be reduced in skeletal muscle of type 2 diabetic patients (7) and a polymorphism in Mfn2 was reported to be associated with type 2 diabetes. These findings point out a possible role of disturbed mitochondrial dynamics in metabolic disease in the presence of substrate excess.

In summary, it is evident that the occurrence of type 2 diabetes is associated with a low mitochondrial capacity in the skeletal muscle. Mitochondrial dysfunction in skeletal muscle occurs at several levels, ranging from morphological perturbations to changes in gene- and protein expression, to impaired function according to in vivo and ex vivo data. However, as most data have been obtained from cross-sectional studies, and subject groups are not always carefully matched for age, body mass index, and physical activity, it is not completely clear as to what extent obesity, age, and physical inactivity contribute to the differences reported. Some studies indicate that even when controlling for these factors, a small but significant difference in mitochondrial function persists (92). Underlying mechanisms, such as ROS levels and increased fission, are currently under investigation (26a).

\section{Mitochondrial dysfunction in cardiac muscle}

It is well known that type 2 diabetic patients have an increased risk of developing heart failure (21). In overt heart failure, ATP production becomes insufficient to sustain normal contraction (37); thus, mitochondrial involvement is evident. However, early mitochondrial changes due to diabetes are less well established in humans (87a). The first evidence of disturbances in energy metabolism in cardiac muscle of diabetic patients stems from ${ }^{31} \mathrm{P}$ MRS studies investigating cardiac PCr/ATP ratio in vivo
FIG. 2. Schematic representation of the complex relationship between high lipid availability and mitochondrial dysfunction. High lipid availability can cause diminished mitochondrial function via increased ROS levels and lipid peroxidation (89). Impaired mitochondrial function, in turn, can limit fat oxidative capacity, disturbing the balance between lipid availability and lipid use, further increasing lipid surplus in a vicious cycle. Alternatively, high lipid availability can directly affect electron transport in the respiratory chain (1). Combined with high levels of glucose, lipid surplus can hamper mitochondrial dynamics (103), interfering with normal mitochondrial quality control, thereby contributing to the deterioration of mitochondrial function. ROS, reactive oxygen species.

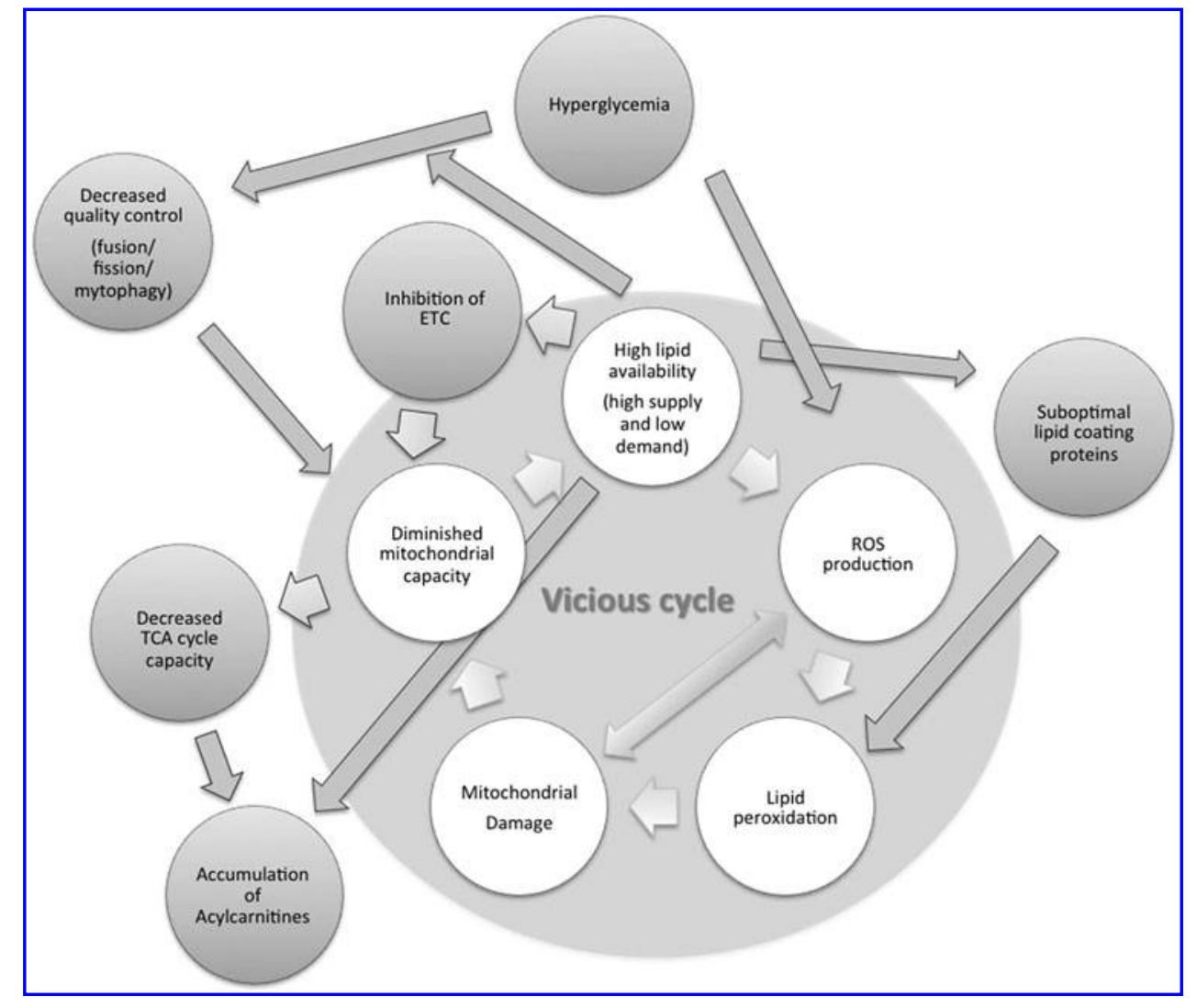


in "asymptomatic" patients $(23,87)$. The $\mathrm{PCr} / \mathrm{ATP}$ ratio is considered an indicator of cardiac energy status, as $\mathrm{PCr}$ hydrolysis is the first rescue to maintain ATP concentration in the face of insufficient ATP synthesis (see phosphorus spectrum in Fig. 3). Therefore, mitochondrial dysfunction is expected to result in a decreased PCr/ATP ratio. Remarkably, mild diminishment of PCr/ATP ratio already occurs at a very early stage, when patients are asymptomatic with respect to cardiac disease $(23,87)$. This hints at a possible causal role of mitochondrial aberrations increasing the heart susceptibility to failure. Two independent studies reported decreased cardiac PCr/ATP ratio by $20 \%-35 \%$ in patients suffering from type 2 diabetes $(23,87)$.

A recent study showed increasing deterioration of mitochondrial metabolism in pigs during development of paceinduced heart failure, according to lessened conversion of hyperpolarized pyruvate to glutamate and $\mathrm{CO}_{2}(94)$. "Hyperpolarization" of pyruvate enhances manifold the nuclear magnetic resonance sensitivity of this metabolite, making it possible to observe its processing further into downstream metabolites (e.g., glutamate and $\mathrm{CO}_{2}$ ), even if concentrations are low. Interestingly, the steady decrease in oxidative pyruvate metabolism that precedes the manifestation of heart failure was paralleled by a similar decrease in $\mathrm{PCr} / \mathrm{ATP}$ levels, both of which were measured noninvasively by MRS. These data suggest that the PCr/ATP ratio may indeed be a valuable marker of cardiac mitochondrial function at the onset of heart failure.

As in skeletal muscle, mitochondrial function of the heart can be affected by perturbations in many processes such as biogenesis, increased damage via ROS, and decreased quality control. A few recent studies $(3,67,73)$ sampled atrial tissue in diabetic and control subjects during coronary artery bypass graft surgery. During such a surgery, a small atrial sample could be taken to investigate this in greater detail in humans $(3,67,73)$. Two studies investigated ex vivo mitochondrial function in atrial tissue by high-resolution respirometry in diabetic patients and control subjects, and both found defects

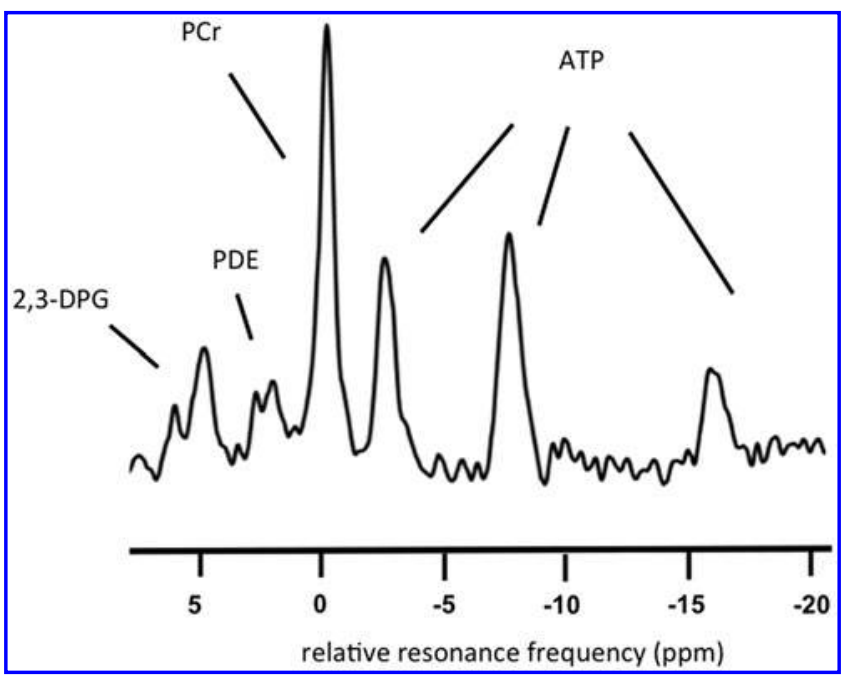

FIG. 3. ${ }^{31} \mathrm{P}$ spectrum of the myocardium of a young healthy volunteer, acquired with one-dimensional MR spectroscopic imaging. The resonances of 2,3-DPG, PDE, PCr, and ATP are depicted. The PCr/ATP ratio can be calculated as a parameter of energy status. PDE, phosphodiesters. in atrial myofibers from diabetic patients. While Anderson et al. (3) found no difference in state 3 respiration on pyruvate or succinate in diabetic patients, state 3 respiration was lower in permeabilized heart muscle fibers from diabetic subjects when supported by glutamate/malate. Since the latter substrate combination feeds complex I of the respiratory chain, these findings suggest a complex I abnormality in cardiac mitochondria from diabetic patients. The emission of $\mathrm{H}_{2} \mathrm{O}_{2}$ was also higher in diabetic atrial tissue, either in the presence of increasing concentrations of succinate while inhibiting ATPase with oligomycin or during submaximal state 3 respiration. Furthermore, a more oxidative milieu was found in diabetic patients, as can be judged by a higher concentration of oxidized glutathione (GSSG) with respect to total glutathione (GSHt). Oxidative stress was further demonstrated by higher steady-state lipid peroxidation and nitrosation as assessed by immunoblot of proteins from atrial homogenates (hydroxynonenal [HNE] and 3-nitrotyrosine modified proteins).

While these results indicate impaired mitochondrial function, no evidence for decreased mitochondrial biogenesis was found, as PGC- $1 \alpha$ expression and peroxisome proliferatoractivated receptor $\alpha(\operatorname{PPAR} \alpha)$ protein levels were unchanged (3). In the second, more recent study, Montaigne et al. (67) showed that several respiratory chain complex activities, namely from complex II and III, were lowered in atrial tissue from diabetic patients compared with nondiabetic patients. Furthermore, state 3 respiration supported by fatty acid-like, pyruvate, or succinate substrates was reduced in permeabilized fibers in cardiac tissue from diabetic patients. These data also point out an inefficient generation of ATP, as indicated by a poor coupling of oxidative phosphorylation (i.e., low respiratory control ratio $[R C R]$ on palmitate and pyruvatesupported respiration in diabetic tissue).

Furthermore, an increased atrial ROS production (as measured by electron paramagnetic resonance spectroscopy) and elevated activity of anti-oxidant enzymes (mitochondrial MnSOD and cytosolic catalase) were found (67). Again, also in this study, no defect in PGC- $1 \alpha$ expression was detected. Together with the finding that citrate synthase activity and mitochondrial density (as determined by electron microscopy) were similar in the cardiac tissue of diabetic patients and the control subjects, these data indicate normal mitochondrial biogenesis in the human diabetic heart (67). The disturbance in mitochondrial function might be relevant for contractile function, since diabetes was also associated with pronounced contractile dysfunction in these patients. The twitch force that developed ex vivo by atrial trabeculae from diabetic patients was significantly lower than in nondiabetic subjects. Although $\mathrm{Ca}^{2+}$ handling was also affected in the hearts from diabetic patients and the $\mathrm{Ca}^{2+}$ retention correlated with $e x$ vivo twitch force, the latter was also correlating with parameters of mitochondrial function, suggesting a possible link between these two functional variables. It was proposed that hyperglycemia may be at the basis of the mitochondrial impairments, as parameters of mitochondrial function correlated negatively with $\mathrm{HbA1C}$ plasma concentrations (67).

Furthermore, mitochondria were smaller in atrial tissue from diabetic patients and the expression of fusion-related MFN1 protein was lower in tissue from diabetic patients and correlated negatively with $\mathrm{HbA1C}$ plasma concentrations. However, other dynamic-related proteins were unchanged (67). 
In summary, there is convincing evidence from in vivo and ex vivo studies that cardiac mitochondrial function is disturbed in the diabetic state. The underlying mechanism seems not to be related to altered PGC- $1 \alpha$ or PPAR expression and mitochondrial biogenesis, while mitochondria of diabetic patients show more uncoupling, higher ROS production, and changes in their fusion-fission dynamics. In this setting, the increased uncoupling may be at least partially due to the activation of uncoupling proteins (UCP2,3), which are known to be regulated by oxidative stress (14). This may be a protective mechanism, reducing oxidative stress at the cost of efficiency. In that respect, it has been shown that $\mathrm{db} / \mathrm{db}$ mice are characterized by increased ROS and enhanced mitochondrial uncoupling (13). This notion is further supported by the finding that a polymorphism that results in lower transcription of UCP2 was associated with oxidative stress in humans (85).

\section{Functional Consequences of Mitochondrial Dysfunction for Insulin Resistance in Humans}

Insulin sensitivity in skeletal muscle is an important determinant of whole body insulin action, as skeletal muscle is the major site of insulin-stimulated glucose uptake (22). Increased skeletal muscle lipid content (intramyocellular lipid [IMCL]) has been repeatedly found to be strongly related to insulin resistance $(39,50,77)$ and elevated in type 2 diabetic patients as well as in subjects with an increased risk of developing diabetes later in life (39).

In endurance trained athletes, who are also characterized by high IMCL levels, this correlation between IMCL and insulin resistance is, however, absent. In that context, it was emphasized by us and others that the combination of high lipid availability and low oxidative capacity may be at the basis of insulin resistance. Seemingly, lipid infusion has a less pronounced effect in hampering insulin sensitivity in subjects with a high mitochondrial capacity. During lipid infusion, insulin sensitivity decreased by only $29 \%$ in endurance trained subjects as compared with $63 \%$ in untrained subjects (81), suggesting that a high mitochondrial function could protect from diabetes.

Currently, there are different hypotheses on how mitochondrial dysfunction, in concert with a high lipid bioavailability (high IMCL), could hamper insulin sensitivity in the skeletal muscle. On the one hand, a predisposition for low mitochondrial function and therefore low fat oxidative capacity was suggested to be causing IMCL accumulation in sedentary subjects in the first place (80). In turn, intracellular lipid excess with respect to demand might be hampering insulin signaling via cytosolic accumulation of lipid intermediates such as diacylglycerol (DAG), ceramides of long-chain acyl-CoA or long-chain acyl-carnitine species (58). The consequences of high lipid bioavailability may be aggravated by suboptimal "packaging" of lipid droplets (IMCL) by lipid coating proteins (as recently reviewed in Ref. 11).

Alternatively to the suggestion of an initial defect in mitochondria, their reduced function may also be a consequence of high fatty acid abundance, causing mitochondrial damage via increased ROS levels and lipid peroxidation (89). Similarly, an imbalance between mitochondrial tricarboxylic acid (TCA) cycle activity and lipid availability was suggested to lead to fatty acids being trapped in the form of long-chain acyl-carnitine hampering insulin sensitivity directly (2) or diminishing the availability of free carnitine, which was also associated with insulin resistance $(55,75)$.

Finally, a vicious cycle of weakened mitochondrial capacity and quality on the one hand, and excessive lipid substrate on the other hand, may be at the basis of cellular changes, leading to the development of insulin resistance (Fig. 2). Interestingly, diminished mitochondrial function was also shown to be associated with a loss of muscle mass (sarcopenia) (43). As skeletal muscle is responsible for the main part of insulininduced glucose uptake, the loss of muscle mass, for example, during aging, further aggravates whole-body insulin resistance.

Although several mechanisms have been proposed to mediate insulin resistance during metabolic challenge, the exact mechanisms of how insulin sensitivity is diminished are yet unknown.

The debate on how mitochondrial fatty acid load and oxidative capacity are related to insulin resistance is also highly relevant for cardiac muscle. Insulin resistance in the heart is less crucial for whole-body glucose uptake, but it makes the heart inflexible with respect to substrate selection. Ultimately, this may increase the susceptibility to cardiac injury and apoptosis.

In the heart, an oversupply of lipids seems to be central in the initiation of unfavorable metabolic remodeling and insulin resistance as seen in diabetic cardiomyopathy. In overweight and diabetic humans, elevated cardiac fat content in the heart is observed (61), investigated with MRS (see lipid spectrum in Fig. 4). It has been proposed that elevated $\operatorname{PPAR} \alpha$ activation, due to increased fatty acid availability, is involved (25). PPAR activation stimulates mitochondrial biogenesis and increases fatty acid uptake, leading to lipid accumulation in the heart of overweight and diabetic patients. Furthermore, fatty acidinduced PPAR $\alpha$ stimulation also augments the expression of pyruvate dehydrogenase kinase 4 (PDK4) that reduces carbohydrate metabolism by inhibiting the conversion of pyruvate to acetyl-CoA, thereby hampering the entry of the end product of glycolysis to the TCA cycle.

Although PDK4 activation would favor the oxidation of fatty acids, it also diminishes an insulin-stimulated switch to glucose oxidation, making the heart less metabolically flexible and insulin resistant. Furthermore, the accumulation of cardiac lipids is associated with the formation of lipid metabolites that were shown to interfere with insulin signaling in vitro, such as DAG and ceramides $(17,42)$. This would decrease metabolic flexibility in the heart and increase its dependence on fatty acids. Importantly, the high rates of fatty acid oxidation in the heart are associated with elevated oxygen consumption and high ROS production (57). In turn, ROS are believed to be able to damage mitochondria, lowering their function in diabetes $(10,99)$. In particular, cardiolipin, a phospholipid that stabilizes the inner mitochondrial membrane, was shown to be prone to oxidative damage (53). Therefore, mitochondrial quality and optimal functioning of the mitochondrial network seems to be challenged in the presence of high lipid availability and insulin resistance.

\section{Mitochondrial Function as a Target to Improve Insulin Sensitivity?}

Although the mechanisms underlying the link between mitochondrial function, ectopic lipid storage, and insulin 


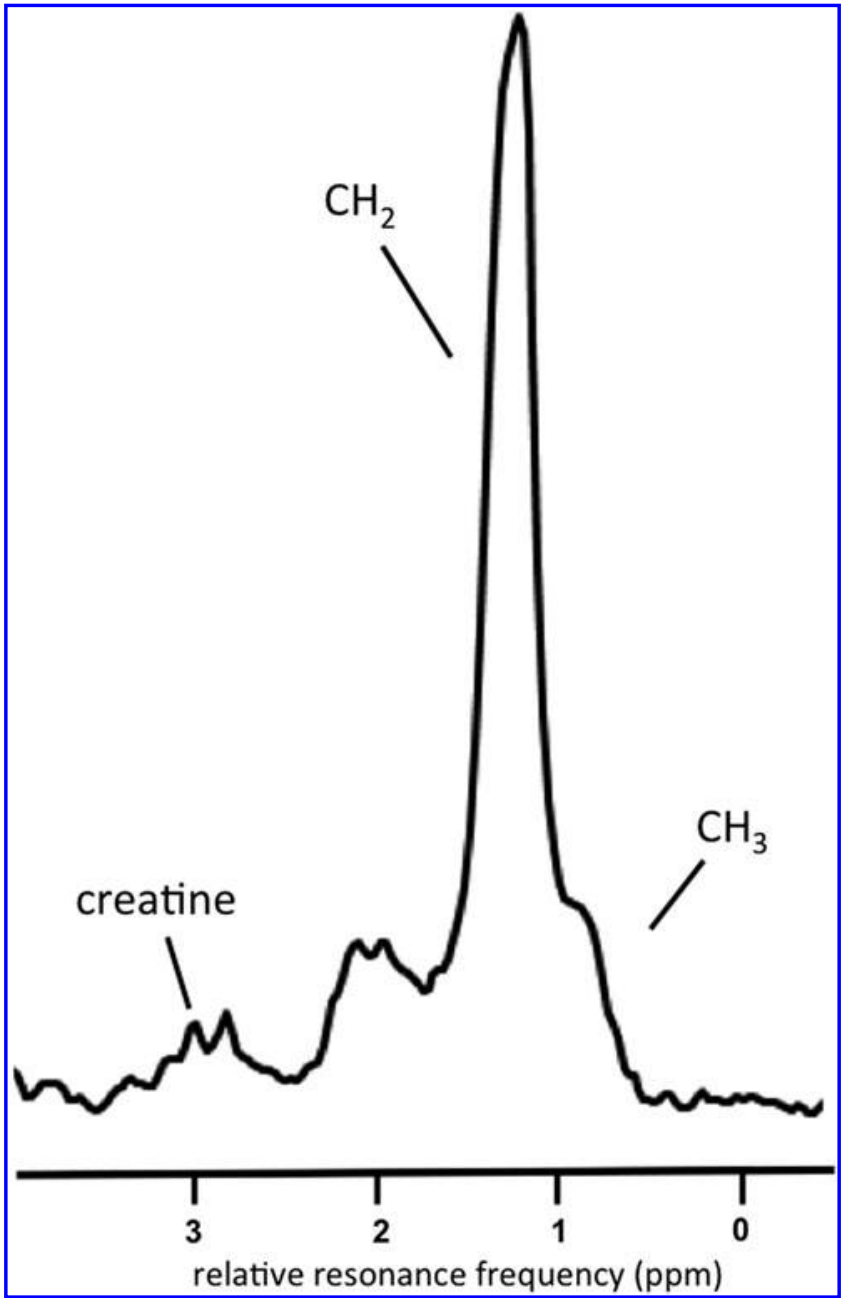

FIG. 4. ${ }^{1} \mathrm{H}$ spectrum of the interventricular septum of the heart of a healthy volunteer with elevated BMI $(B M I=30)$, acquired with MR spectroscopy. The lipid resonances of the $\mathrm{CH} 2$ and $\mathrm{CH} 3$ group of fatty acids are depicted. Using the unsuppressed water resonance (not shown), a fat/water ratio can be calculated to quantify the cardiac fat fraction.

resistance are still not completely unraveled, accumulating evidence shows that improvement in mitochondrial function and quality in skeletal muscle have a positive effect on insulin sensitivity, while less is known about the human heart.

\section{Physical activity and exercise training to improve mitochondrial capacity}

A robust way to improve the ATP-generating capacity of the mitochondrial system is by physical activity training. It is well known that contraction in the skeletal muscle activates AMP-activated protein kinase (AMPK) and induces expression of PGC-1 $\alpha$, nuclear respiratory factor 1 (NRF-1), and NRF-2, resulting in increased transcription of mitochondrial proteins and stimulation of mitochondrial biogenesis $(9,59)$. Therefore, regular exercise consistently activates these pathways, which in the long term lead to a higher mitochondrial capacity, at least partly due to an increased mitochondrial density. Studies from our group and others reported enhanced mitochondrial function in vivo in response to physical activity programs consisting of endurance and strength training ranging from 2 weeks to 1 year (26, $62,63,101)$. Exercise training also leads to an elevated content in cardiolipin, known to be necessary for the assembly of respiratory chain complexes in the inner mitochondrial membrane (100). Importantly, type 2 diabetic patients were just as responsive as healthy subjects to exercise-induced improvements in mitochondrial function (63).

Training-induced improvements in in vivo mitochondrial function (as determined by ${ }^{31} \mathrm{P}-\mathrm{MRS}$ ) were accompanied by increased mitochondrial oxidative capacity determined ex vivo using high-resolution respirometry (63). In fact, the reduced mitochondrial function observed in type 2 diabetic patients could be completely restored to control values in endurance training programs as short as 3 months. Enhanced mitochondrial function is also paralleled by decreased insulin resistance and augmented IMCL content.

These data show at least an association between improved mitochondrial function and insulin sensitivity in humans. It should be noted that the insulin-sensitizing effect of exercise training has long been recognized $(34,49)$, although the exact underlying mechanism leading to a more prominent insulininduced translocation of GLUT4 in the trained state is still unclear. While it is remarkable that exercise-elicited enhancement of mitochondrial function is accompanied by improved insulin sensitivity, it should be acknowledged that exercise training causes various adaptations and it is unknown as to what extent the resulting improvement in mitochondrial function is responsible for the increased insulin sensitivity.

These adaptations are more difficult to investigate in the human heart, since cardiac tissue is not readily available; thus, for now, we have to rely on animal data or human ${ }^{31} \mathrm{P}-$ MRS studies. In mice, daily swimming increased cardiac expression of transcription factors that orchestrate translation of mitochondrial proteins, such as PGC- $1 \alpha, \mathrm{NRF}-1$, and mitochondrial transcription factor A (Tfam) (102). As in skeletal muscle, mitochondrial biogenesis in the heart is also stimulated by regular exercise, as reported in rodent models. In mice, exercise training increases mitochondrial volume and number (102). All these adaptations were endothelial nitric oxide synthase (eNOS) dependent, underscoring the relevant role of nitric oxide (NO) as a signaling molecule for training-induced cellular remodeling in the heart. In cardiomyocytes, eNOS becomes more active when phosphorylated by AMPK (18) and in the presence of high cellular calcium concentrations. Both cardiac AMPK activity and calcium concentrations are known to be enhanced by exercise (76), probably constituting important signaling routes leading to the improvement of mitochondrial function in the heart (Fig. 5).

Very little data are available in the human heart; however, there are some indications that mitochondrial function is also improved by exercise training. Left ventricular PCr/ATP ratio was found to be elevated in life-long physically active men when compared with sedentary individuals (79), and a correlation between cardiac PCr/ATP and physical fitness was reported in healthy young men (48). However, effects on cardiac energy metabolism were less clear in patients with heart failure who were subjected to an 8-week mild training protocol. The training intervention improved functional 
FIG. 5. Scheme of molecular mechanisms that mediate the beneficial effects of $C R$ and exercise on mitochondrial function. CR and exercise activate AMPK and SIRT that result in phosphorylation $(30,40)$ and deacetylation $(15$, 84) of FOXO and PGC- $1 \alpha$. PGC- $1 \alpha$ and FOXO activation stimulate the transcription of nuclear genes related to mitochondrial function. AMPK, AMP-activated protein kinase; $\mathrm{CR}$, calorie restriction; PGC$1 \alpha$, peroxisome proliferator coactivator $1-\alpha$.

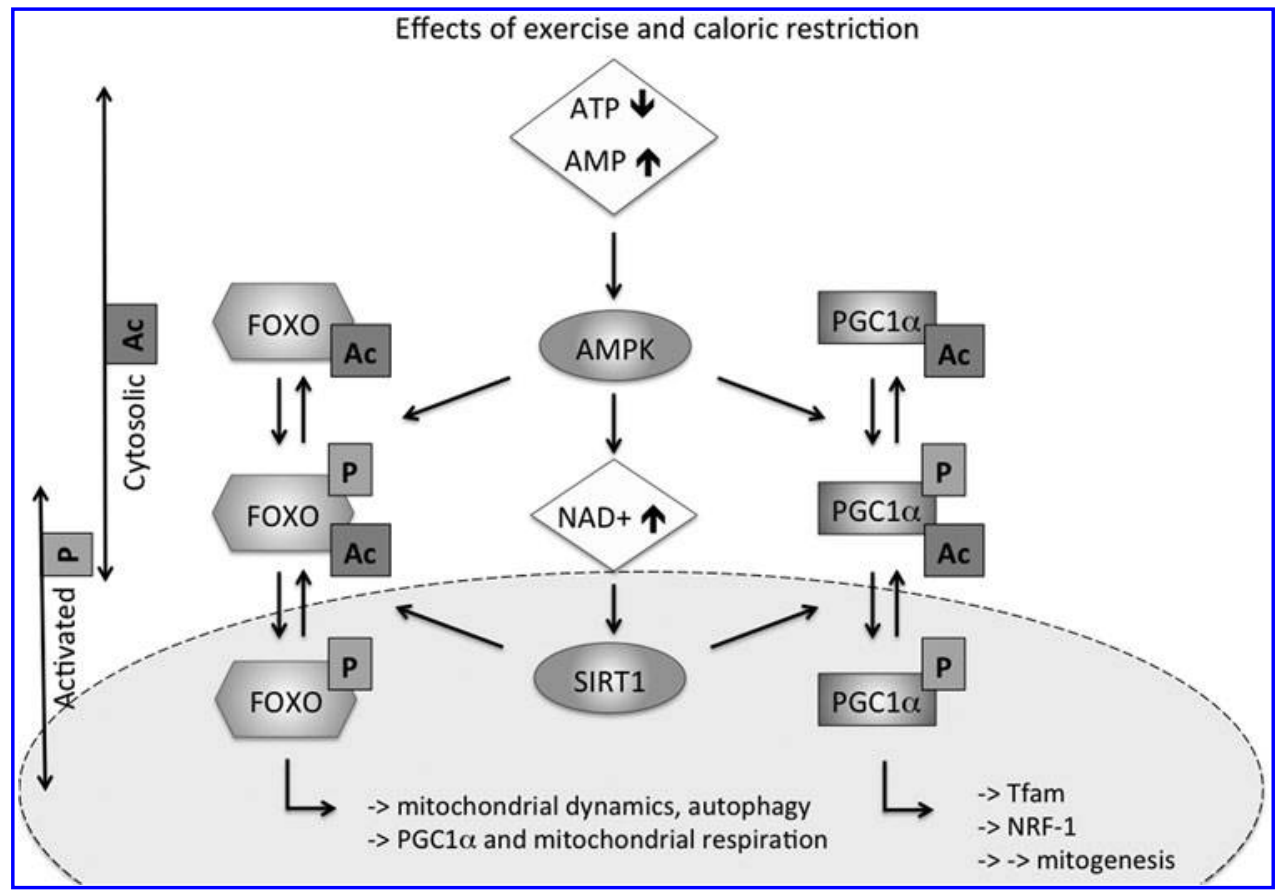

parameters such as left ventricular ejection fraction, but it did not affect the PCr/ATP ratio (33).

It is worth noting that cardiac lipid content, as determined by noninvasive ${ }^{1} \mathrm{H}$-MRS, was decreased after training in overweight/obese subjects. This would be in line with improved mitochondrial function, leading to normalization of cardiac lipid content (91). However, quite strikingly, a reduction in cardiac lipid content with training could only be detected in healthy subjects and did not occur in patients with type 2 diabetes (93). However, the explanation of this differential response to exercise is unclear.

Likewise, mitochondrial quality control in the heart may be beneficially influenced by physical activity, improving mitochondrial respiratory capacity. Induction of autophagy has been reported after endurance training in mice (32). Mfn2, an indicator of mitochondrial fusion activity, was increased in the cardiac muscle of mice after daily swimming (102). Diminished cardiac mitochondrial function in post-infarction rats, characterized by adverse mitochondrial network dynamics (reduced fusion and increased fission), was normalized after aerobic interval training. $\mathrm{RCR}$ and $\mathrm{P} / \mathrm{O}$ were elevated after training and complex I, III, and IV activities were enhanced concomitantly with normalization of markers of mitochondrial fusion (mfn2 and OPA1) and fission (dynamin-related protein 1, DRP1) (41).

In summary, together with higher mitochondrial density, optimization of mitochondrial dynamics may also underlie the training-induced improvement in mitochondrial function, although more data are needed to understand how physical activity affects these processes (26a). Furthermore, more human studies will be necessary to investigate how exercise training may impact cardiac energy metabolism and whether exercise-induced improvement of cardiac function depends on enhanced cardiac mitochondrial function (31a).

\section{Calorie Restriction and Calorie Restriction Mimetics to Improve Mitochondrial Function}

The generally accepted health benefits of physical activity have urged researchers to find alternatives to exercise with the aim of modulating, and potentially improving, mitochondrial function. From cellular studies, it is well known that energy scarcity (fasting, calorie restriction [CR]) leads to PGC- $1 \alpha$ and forkhead box $\mathrm{O}$ protein (FOXO) activation, increasing the transcription of mitochondrial genes in various cell types $(5$, 71). PGC- $1 \alpha$ and FOXO need to be phosphorylated by AMPK $(30,40)$ and acetylated by sirtuin 1 (SIRT1) $(15,84)$ to become active (Fig. 5). Furthermore, there are indications that CR increases autophagy (8) (by deacetylation of autophagy protein 5 (Atg5) and Atg7, via SIRT activation) (104), which may reflect a more stringent control of mitochondrial quality. Mitochondrial efficiency is increased with CR, preserving ATP generation at a lower oxygen cost while producing less ROS (56). Indeed, in vitro results show that the number of low-potential mitochondria is increased on CR (56).

These findings were mostly confirmed in both skeletal muscle and the heart in rodents ex vivo, with very pronounced reductions in ROS generation. Still, there is some discussion about the postulated stimulation of mitochondrial biogenesis by CR according to recent studies showing contradictory results (reviewed in Ref. 29). Nevertheless, human data are still very limited, even for skeletal muscle. One study showed that $\mathrm{CR}$ can indeed improve mitochondrial function also in humans. Six months of $25 \% \mathrm{CR}$ in young overweight subjects improved oxidative capacity and increased the expression of PGC- $1 \alpha$, TFAM, and SIRT1, as well as of mtDNA content in skeletal muscle tissue (19). On the other hand, weight reduction studies have not been consistent in reporting improved mitochondrial function (24).

In a very small study with overweight male subjects, $\mathrm{VO}_{2 \max }$ increased after $25 \% \mathrm{CR}$ for 7 weeks together with 
AMPK and SIRT activation in peripheral blood mononuclear cells. Interestingly, muscle cells that were cultured in serum from these calorie-restricted subjects showed an increase in both AMPK and SIRT activities and mitochondrial biogenesis (47). In another human study, long-term CR influenced transcriptional activity of the insulin-like growth factor/insulin signaling, mitochondrial biogenesis, and inflammation pathways, as evaluated by gene expression profiling (51).

For the heart, we have to rely largely on rodent studies. In mice, $\mathrm{CR}$ was shown to induce mitochondrial biogenesis by upregulating PGC- $1 \alpha, \mathrm{NRF}-1$, and TFAM (74). In addition, MFN1 and MFN2 were induced, indicating changes in mitochondrial dynamics (74). In rats, CR decreased the amount of acetylated mitochondrial proteins in the heart and, although not different with respect to the basal state, mitochondrial function was preserved on ischemia/reperfusion in the restricted group only, and this was accompanied by lower $\mathrm{H}_{2} \mathrm{O}_{2}$ emission (96). Interestingly, the CR-mediated adaptation also produced functional consequences, since $\mathrm{CR}$ ameliorates aging-related diastolic dysfunction in rats (95).

Research on the health benefits of CR has also stimulated the search for compounds that could mimic its effects. In this context, sirtuins activation is a desired effect. One of the compounds that has received much attention lately is resveratrol $(90,96 a)$. Resveratrol $\left(3,5,4^{\prime}\right.$ trihydroxystilbene $)$ is a polyphenol naturally present in several plants, and it is identified as a small-molecule activator of sirtuin 1 (SIRT1) (36). Resveratrol is believed to have CR-like effects, making it a promising candidate for treatment and prevention of metabolic diseases $(16,98,105)$.

In humans, we showed that supplementing overweight healthy men with resveratrol improved skeletal muscle mitochondrial efficiency according to ex vivo high-resolution respirometry and the maximal mitochondrial respiration attained in the presence of complex I and complex II substrates. Furthermore, gene enrichment analysis revealed that resver- atrol activates mitochondrial pathways related to ATP synthesis and oxidative phosphorylation. In accordance with earlier rodent data, resveratrol supplementation increased citrate synthase and AMPK activities while inducing increased SIRT1 protein levels in the skeletal muscle (98).

Regarding cardiac function, many beneficial effects of resveratrol on the rodent heart have been described; unfortunately, very little is known about its effects on the human myocardium. In aged rats, a comparatively similar increase in fractional shortening was determined after resveratrol treatment or endurance training. However, only resveratrol was able to protect against apoptosis (54). Resveratrol prevented adverse cardiac remodeling on pressure overload in mice. Likewise, markers of oxidative stress, cardiac hypertrophy, inflammation, fibrosis, hypoxia, and apoptosis, all of which were increased in response to pressure overload, were significantly reduced in the mice group treated with resveratrol (31). However, the occurrence of these salutary effects remains to be investigated in humans.

Clearly, more human data is needed on the impact of nutritional and/or pharmacological activation of mitochondrial metabolism on skeletal muscle insulin sensitivity and cardiac function. Currently, some registered drugs are known to be ligands of mitochondrial transcription factors and promote mitochondrial biogenesis, such as, for example, fibrates or glitazones that bind to $\operatorname{PPAR} \alpha$ or $\operatorname{PPAR} \gamma$, respectively. Currently, any of the currently used drugs are as efficient as a healthy lifestyle, and more specific mitochondrial compounds need to be tested. In spite of the progress achieved in understanding mitochondrial function and how it can be boosted, current knowledge indicates that the most effective and safest way to stimulate mitochondrial function is via a moderate caloric intake and physical activity.

In conclusion, improving mitochondrial function has beneficial effects on insulin sensitivity, although the mechanisms are not yet fully elucidated. Since the skeletal muscle is the main organ responsible for insulin-stimulated glucose

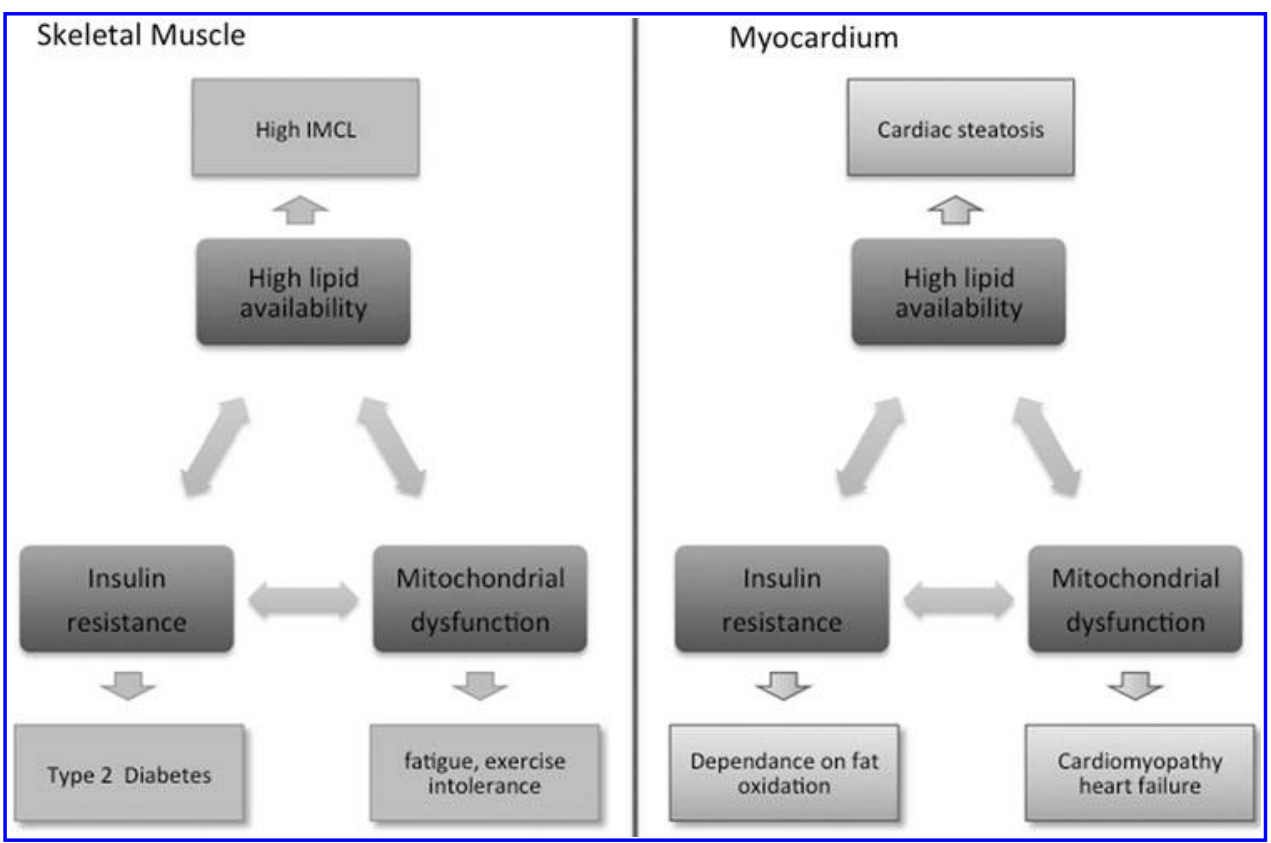

FIG. 6. High lipid availability, mitochondrial dysfunction, and insulin resistance interrelationship, and their consequences in cardiac and skeletal muscle. Mitochondrial dysfunction is associated with tissue dysfunction in both organs, resulting in insulin resistance, exercise intolerance, and cardiomyopathy. Insulin resistance in the skeletal muscle is an early hallmark of type 2 diabetes development. In the heart, insulin resistance increases the dependence on fat oxidation. High lipid availability and accumulation of intracellular fat are the most likely involved in the development of insulin resistance and mitochondrial dysfunction. 
uptake, the improvement of mitochondrial function is a promising target to improve whole body insulin sensitivity in type 2 diabetic patients (Fig. 6). This is even more important, as mitochondrial impairment has been shown to lead to muscle mass reduction.

In the heart, the available data from animal studies suggest that improvement of mitochondrial function can reverse aging-induced changes (Fig. 6). Interventions that improve mitochondrial function are protective against cardiomyopathy and ischemia/reperfusion damage. More studies are needed to confirm these findings in humans.

\section{Acknowledgments}

V.S.-H. is supported by a VENI grant (Grant No. 91611136) for innovative research from the Netherlands Organization for Scientific Research (NWO). M.E.K. is supported by an Aspasia grant (Grant No. 015.008.047) from the Netherlands Organization for Scientific Research (NWO).

\section{References}

1. Abdul-Ghani MA, Muller FL, Liu Y, Chavez AO, Balas B, Zuo P, Chang Z, Tripathy D, Jani R, Molina-Carrion M, Monroy A, Folli F, Van Remmen H, and DeFronzo RA. Deleterious action of FA metabolites on ATP synthesis: possible link between lipotoxicity, mitochondrial dysfunction, and insulin resistance. Am J Physiol Endocrinol Metab 295: E678-E685, 2008.

2. Aguer C, McCoin CS, Knotts TA, Thrush AB, Ono-Moore K, McPherson R, Dent R, Hwang DH, Adams SH, and Harper ME. Acylcarnitines: potential implications for skeletal muscle insulin resistance. FASEB J 29: 336-345, 2015.

3. Anderson EJ, Kypson AP, Rodriguez E, Anderson CA, Lehr EJ, and Neufer PD. Substrate-specific derangements in mitochondrial metabolism and redox balance in the atrium of the type 2 diabetic human heart. $\mathrm{J} \mathrm{Am} \mathrm{Coll}$ Cardiol 54: 1891-1898, 2009.

4. Anderson EJ, Lustig ME, Boyle KE, Woodlief TL, Kane DA, Lin CT, Price JW, 3rd, Kang L, Rabinovitch PS, Szeto $\mathrm{HH}$, Houmard JA, Cortright RN, Wasserman DH, and Neufer PD. Mitochondrial $\mathrm{H} 2 \mathrm{O} 2$ emission and cellular redox state link excess fat intake to insulin resistance in both rodents and humans. J Clin Invest 119: 573-581, 2009.

5. Anderson RM, Barger JL, Edwards MG, Braun KH, O'Connor CE, Prolla TA, and Weindruch R. Dynamic regulation of PGC-1alpha localization and turnover implicates mitochondrial adaptation in calorie restriction and the stress response. Aging Cell 7: 101-111, 2008.

6. Babbar M and Sheikh MS. Metabolic stress and disorders related to alterations in mitochondrial fission or fusion. Mol Cell Pharmacol 5: 109-133, 2013.

7. Bach D, Naon D, Pich S, Soriano FX, Vega N, Rieusset J, Laville M, Guillet C, Boirie Y, Wallberg-Henriksson H, Manco M, Calvani M, Castagneto M, Palacin M, Mingrone G, Zierath JR, Vidal H, and Zorzano A. Expression of Mfn2, the Charcot-Marie-Tooth neuropathy type 2A gene, in human skeletal muscle: effects of type 2 diabetes, obesity, weight loss, and the regulatory role of tumor necrosis factor alpha and interleukin-6. Diabetes 54: 2685-2693, 2005.

8. Bergamini E, Cavallini G, Donati A, and Gori Z. The antiageing effects of caloric restriction may involve stimula- tion of macroautophagy and lysosomal degradation, and can be intensified pharmacologically. Biomed Pharmacother 57: 203-208, 2003.

9. Bergeron R, Ren JM, Cadman KS, Moore IK, Perret P, Pypaert M, Young LH, Semenkovich CF, and Shulman GI. Chronic activation of AMP kinase results in NRF-1 activation and mitochondrial biogenesis. Am J Physiol Endocrinol Metab 281: E1340-E1346, 2001.

10. Bhatt NM, Aon MA, Tocchetti CG, Shen X, Dey S, Ramirez-Correa G, O'Rourke B, Gao WD, and Cortassa S. Restoring redox balance enhances contractility in heart trabeculae from type 2 diabetic rats exposed to high glucose. Am J Physiol Heart Circ Physiol 308: H291-302, 2015.

11. Bosma M, Kersten S, Hesselink MK, and Schrauwen P. Re-evaluating lipotoxic triggers in skeletal muscle: relating intramyocellular lipid metabolism to insulin sensitivity. Prog Lipid Res 51: 36-49, 2012.

12. Boudina $\mathrm{S}$ and Abel ED. Mitochondrial uncoupling: a key contributor to reduced cardiac efficiency in diabetes. Physiology 21: 250-258, 2006.

13. Boudina S, Sena S, Theobald H, Sheng X, Wright JJ, Hu XX, Aziz S, Johnson JI, Bugger H, Zaha VG, and Abel ED. Mitochondrial energetics in the heart in obesityrelated diabetes: direct evidence for increased uncoupled respiration and activation of uncoupling proteins. Diabetes 56: 2457-2466, 2007.

14. Brand MD and Esteves TC. Physiological functions of the mitochondrial uncoupling proteins UCP2 and UCP3. $\underline{\text { Cell }}$ Metab 2: 85-93, 2005.

15. Brunet A, Sweeney LB, Sturgill JF, Chua KF, Greer PL, Lin Y, Tran H, Ross SE, Mostoslavsky R, Cohen HY, Hu LS, Cheng HL, Jedrychowski MP, Gygi SP, Sinclair DA, Alt FW, and Greenberg ME. Stress-dependent regulation of FOXO transcription factors by the SIRT1 deacetylase. Science 303: 2011-2015, 2004.

16. Canto $\mathrm{C}$ and Auwerx J. Targeting sirtuin 1 to improve metabolism: all you need is NAD $(+)$ ? Pharmacol Rev 64: 166-187, 2012.

17. Chavez JA and Summers SA. Characterizing the effects of saturated fatty acids on insulin signaling and ceramide and diacylglycerol accumulation in 3T3-L1 adipocytes and C2C12 myotubes. Arch Biochem Biophys 419: 101-109, 2003.

18. Chen ZP, Mitchelhill KI, Michell BJ, Stapleton D, Rodriguez-Crespo I, Witters LA, Power DA, Ortiz de Montellano PR, and Kemp BE. AMP-activated protein kinase phosphorylation of endothelial NO synthase. FEBS Lett 443: 285-289, 1999.

19. Civitarese AE, Carling S, Heilbronn LK, Hulver MH, Ukropcova B, Deutsch WA, Smith SR, and Ravussin E. Calorie restriction increases muscle mitochondrial biogenesis in healthy humans. PLoS Med 4: e76, 2007.

20. De Feyter HM, van den Broek NM, Praet SF, Nicolay K, van Loon LJ, and Prompers JJ. Early or advanced stage type 2 diabetes is not accompanied by in vivo skeletal muscle mitochondrial dysfunction. Eur J Endocrinol 158: 643-653, 2008.

21. de Simone G, Devereux RB, Chinali M, Lee ET, Galloway JM, Barac A, Panza JA, and Howard BV. Diabetes and incident heart failure in hypertensive and normotensive participants of the strong heart study. Am J Hypertens 28: 353-360, 2010.

22. DeFronzo RA, Jacot E, Jequier E, Maeder E, Wahren J, and Felber JP. The effect of insulin on the disposal of 
intravenous glucose. Results from indirect calorimetry and hepatic and femoral venous catheterization. Diabetes 30: 1000-1007, 1981.

23. Diamant M, Lamb HJ, Groeneveld Y, Endert EL, Smit JW, Bax JJ, Romijn JA, de Roos A, and Radder JK. Diastolic dysfunction is associated with altered myocardial metabolism in asymptomatic normotensive patients with well-controlled type 2 diabetes mellitus. $\underline{J \text { Am Coll }}$ Cardiol 42: 328-335, 2003.

24. Dube JJ, Amati F, Toledo FG, Stefanovic-Racic M, Rossi A, Coen P, and Goodpaster BH. Effects of weight loss and exercise on insulin resistance, and intramyocellular triacylglycerol, diacylglycerol and ceramide. Diabetologia 54: 1147-1156, 2011.

25. Finck BN, Han X, Courtois M, Aimond F, Nerbonne JM, Kovacs A, Gross RW, and Kelly DP. A critical role for PPARalpha-mediated lipotoxicity in the pathogenesis of diabetic cardiomyopathy: modulation by dietary fat content. Proc Natl Acad Sci U S A 100: 1226-1231, 2003.

26. Forbes SC, Slade JM, and Meyer RA. Short-term highintensity interval training improves phosphocreatine recovery kinetics following moderate-intensity exercise in humans. Appl Physiol Nutr Metab 33: 1124-1131, 2008.

26a. Galloway CA and Yoon Y. Mitochondrial dynamics in diabetic cardiomyopathy. Antioxid Redox Signal 22: 1545$1562,2015$.

27. Galloway CA and Yoon Y. Mitochondrial morphology in metabolic diseases. Antioxid Redox Signal 19: 415-430, 2013.

28. Giacco F and Brownlee M. Oxidative stress and diabetic complications. Circ Res 107: 1058-1070, 2010.

29. Gouspillou G and Hepple RT. Facts and controversies in our understanding of how caloric restriction impacts the mitochondrion. Exp Gerontol 48: 1075-1084, 2013.

30. Greer EL, Oskoui PR, Banko MR, Maniar JM, Gygi MP, Gygi SP, and Brunet A. The energy sensor AMP-activated protein kinase directly regulates the mammalian FOXO3 transcription factor. J Biol Chem 282: 30107-30119, 2007.

31. Gupta PK, DiPette DJ, and Supowit SC. Protective effect of resveratrol against pressure overload-induced heart failure. Food Sci Nutr 2: 218-229, 2014.

31a. Hafstad AD, Boardman N, and Aasum E. How exercise may amend metabolic disturbances in diabetic cardiomyopathy. Antioxid Redox Signal 22: 1587-1605, 2015.

32. He C, Bassik MC, Moresi V, Sun K, Wei Y, Zou Z, An Z, Loh J, Fisher J, Sun Q, Korsmeyer S, Packer M, May HI, Hill JA, Virgin HW, Gilpin C, Xiao G, Bassel-Duby $\mathrm{R}$, Scherer PE, and Levine B. Exercise-induced BCL2regulated autophagy is required for muscle glucose homeostasis. Nature 481: 511-515, 2012.

33. Holloway CJ, Dass S, Suttie JJ, Rider OJ, Cox P, Cochlin LE, Jackson H, Fast AM, Johnson AW, Karamitsos TD, Neubauer S, and Clarke K. Exercise training in dilated cardiomyopathy improves rest and stress cardiac function without changes in cardiac high energy phosphate metabolism. Heart 98: 1083-1090, 2012.

34. Horton ES. Exercise and physical training: effects on insulin sensitivity and glucose metabolism. Diabetes Metab Rev 2: 1-17, 1986.

35. Houstis N, Rosen ED, and Lander ES. Reactive oxygen species have a causal role in multiple forms of insulin resistance. Nature 440: 944-948, 2006.

36. Howitz KT, Bitterman KJ, Cohen HY, Lamming DW, Lavu S, Wood JG, Zipkin RE, Chung P, Kisielewski A,
Zhang LL, Scherer B, and Sinclair DA. Small molecule activators of sirtuins extend Saccharomyces cerevisiae lifespan. Nature 425: 191-196, 2003.

37. Ingwall JS and Weiss RG. Is the failing heart energy starved? On using chemical energy to support cardiac function. Circ Res 95: 135-145, 2004.

38. Itani SI, Ruderman NB, Schmieder F, and Boden G. Lipid-induced insulin resistance in human muscle is associated with changes in diacylglycerol, protein kinase C, and IkappaB-alpha. Diabetes 51: 2005-2011, 2002.

39. Jacob S, Machann J, Rett K, Brechtel K, Volk A, Renn W, Maerker E, Matthaei S, Schick F, Claussen CD, and Haring HU. Association of increased intramyocellular lipid content with insulin resistance in lean nondiabetic offspring of type 2 diabetic subjects. Diabetes 48: 11131119, 1999.

40. Jager S, Handschin C, St-Pierre J, and Spiegelman BM. AMP-activated protein kinase (AMPK) action in skeletal muscle via direct phosphorylation of PGC-1alpha. Proc Natl Acad Sci U S A 104: 12017-12022, 2007.

41. Jiang HK, Wang YH, Sun L, He X, Zhao M, Feng ZH, Yu $\mathrm{XJ}$, and Zang WJ. Aerobic interval training attenuates mitochondrial dysfunction in rats post-myocardial infarction: roles of mitochondrial network dynamics. Int J Mol Sci 15: 5304-5322, 2014.

42. Jornayvaz FR and Shulman GI. Diacylglycerol activation of protein kinase Cepsilon and hepatic insulin resistance. Cell Metab 15: 574-584, 2012.

43. Joseph AM, Adhihetty PJ, Wawrzyniak NR, Wohlgemuth SE, Picca A, Kujoth GC, Prolla TA, and Leeuwenburgh C. Dysregulation of mitochondrial quality control processes contribute to sarcopenia in a mouse model of premature aging. PLoS One 8: e69327, 2013.

44. Kelley DE, He J, Menshikova EV, and Ritov VB. Dysfunction of mitochondria in human skeletal muscle in type 2 diabetes. Diabetes 51: 2944-2950, 2002.

45. Kemp GJ and Brindle KM. What do magnetic resonancebased measurements of Pi- $>$ ATP flux tell us about skeletal muscle metabolism? Diabetes 61: 1927-1934, 2012.

46. Kemp GJ and Radda GK. Quantitative interpretation of bioenergetic data from $31 \mathrm{P}$ and $1 \mathrm{H}$ magnetic resonance spectroscopic studies of skeletal muscle: an analytical review. Magn Reson Q 10: 43-63, 1994.

47. Kitada M, Kume S, Takeda-Watanabe A, Tsuda S, Kanasaki $\mathrm{K}$, and Koya D. Calorie restriction in overweight males ameliorates obesity-related metabolic alterations and cellular adaptations through anti-aging effects, possibly including AMPK and SIRT1 activation. Biochim Biophys Acta 1830: 4820-4827, 2013.

48. Klug G, Zwick RH, Frick M, Wolf C, Schocke MF, Conci $\mathrm{E}$, Jaschke W, Pachinger O, and Metzler B. Impact of exercise capacity on myocardial high-energy phosphate metabolism. Int J Sports Med 28: 667-672, 2007.

49. Koivisto VA, Yki-Jarvinen $\mathrm{H}$, and DeFronzo RA. Physical training and insulin sensitivity. Diabetes Metab Rev 1: 445-481, 1986.

50. Krssak M, Falk Petersen K, Dresner A, DiPietro L, Vogel SM, Rothman DL, Roden M, and Shulman GI. Intramyocellular lipid concentrations are correlated with insulin sensitivity in humans: a $1 \mathrm{H}$ NMR spectroscopy study. Diabetologia 42: 113-116, 1999.

50a. Kubli DA and Gustafsson AB. Unbreak my heart: Targeting mitochondrial autophagy in diabetic cardiomyopathy. Antioxid Redox Signal 22: 1527-1544, 2015. 
51. Larrouy D, Barbe P, Valle C, Dejean S, Pelloux V, Thalamas C, Bastard JP, Le Bouil A, Diquet B, Clement K, Langin D, and Viguerie N. Gene expression profiling of human skeletal muscle in response to stabilized weight loss. Am J Clin Nutr 88: 125-132, 2008.

52. Larson-Meyer DE, Newcomer BR, Hunter GR, Joanisse DR, Weinsier RL, and Bamman MM. Relation between in vivo and in vitro measurements of skeletal muscle oxidative metabolism. Muscle Nerve 24: 1665-1676, 2001.

53. Lesnefsky EJ and Hoppel CL. Cardiolipin as an oxidative target in cardiac mitochondria in the aged rat. Biochim Biophys Acta 1777: 1020-1027, 2008.

54. Lin CH, Lin CC, Ting WJ, Pai PY, Kuo CH, Ho TJ, Kuo WW, Chang $\mathrm{CH}$, Huang CY, and Lin WT. Resveratrol enhanced FOXO3 phosphorylation via synergetic activation of SIRT1 and PI3K/Akt signaling to improve the effects of exercise in elderly rat hearts. Age 36: 9705, 2014.

55. Lindeboom L, Nabuurs CI, Hoeks J, Brouwers B, Phielix E, Kooi ME, Hesselink MK, Wildberger JE, Stevens RD, Koves T, Muoio DM, Schrauwen P, and SchrauwenHinderling VB. Long-echo time MR spectroscopy for skeletal muscle acetylcarnitine detection. J Clin Invest 124: 4915-4925, 2014.

56. Lopez-Lluch G, Hunt N, Jones B, Zhu M, Jamieson H, Hilmer S, Cascajo MV, Allard J, Ingram DK, Navas P, and de Cabo R. Calorie restriction induces mitochondrial biogenesis and bioenergetic efficiency. Proc Natl Acad Sci US A 103: 1768-1773, 2006.

57. Lorenzo O, Ramirez E, Picatoste B, Egido J, and Tunon J. Alteration of energy substrates and ROS production in diabetic cardiomyopathy. Mediators Inflamm 2013: 461967, 2013.

58. Lowell BB and Shulman GI. Mitochondrial dysfunction and type 2 diabetes. Science 307: 384-387, 2005.

59. Marcinko K and Steinberg GR. The role of AMPK in controlling metabolism and mitochondrial biogenesis during exercise. Exp Physiol 99: 1581-1585, 2014.

60. Marzetti E, Calvani R, Cesari M, Buford TW, Lorenzi M, Behnke BJ, and Leeuwenburgh C. Mitochondrial dysfunction and sarcopenia of aging: from signaling pathways to clinical trials. Int J Biochem Cell Biol 45: 2288-2301, 2013.

61. McGavock JM, Lingvay I, Zib I, Tillery T, Salas N, Unger R, Levine BD, Raskin P, Victor RG, and Szczepaniak LS. Cardiac steatosis in diabetes mellitus: a 1H-magnetic resonance spectroscopy study. Circulation 116: 1170-1175, 2007.

62. McKeough ZJ, Alison JA, Bye PT, Trenell MI, Sachinwalla T, Thompson $\mathrm{CH}$, and Kemp GJ. Exercise capacity and quadriceps muscle metabolism following training in subjects with COPD. Respir Med 100: 1817-1825, 2006.

63. Meex RC, Schrauwen-Hinderling VB, Moonen-Kornips E, Schaart G, Mensink M, Phielix E, van de Weijer T, Sels JP, Schrauwen P, and Hesselink MK. Restoration of muscle mitochondrial function and metabolic flexibility in type 2 diabetes by exercise training is paralleled by increased myocellular fat storage and improved insulin sensitivity. Diabetes 59: 572-579, 2010.

64. Mensink M, Blaak EE, Vidal H, De Bruin TW, Glatz JF, and Saris WH. Lifestyle changes and lipid metabolism gene expression and protein content in skeletal muscle of subjects with impaired glucose tolerance. Diabetologia 46: 1082-1089, 2003.

65. Meyers DE, Basha HI, and Koenig MK. Mitochondrial cardiomyopathy: pathophysiology, diagnosis, and management. Tex Heart Inst J 40: 385-394, 2013.
66. Mogensen M, Sahlin K, Fernstrom M, Glintborg D, Vind $\mathrm{BF}$, Beck-Nielsen H, and Hojlund K. Mitochondrial respiration is decreased in skeletal muscle of patients with type 2 diabetes. Diabetes 56: 1592-1599, 2007.

67. Montaigne D, Marechal X, Coisne A, Debry N, Modine T, Fayad G, Potelle C, El Arid JM, Mouton S, Sebti Y, Duez H, Preau S, Remy-Jouet I, Zerimech F, Koussa M, Richard V, Neviere R, Edme JL, Lefebvre P, and Staels B. Myocardial contractile dysfunction is associated with impaired mitochondrial function and dynamics in type 2 diabetic but not in obese patients. Circulation 130: 554-564, 2014.

68. Montell E, Turini M, Marotta M, Roberts M, Noe V, Ciudad CJ, Mace K, and Gomez-Foix AM. DAG accumulation from saturated fatty acids desensitizes insulin stimulation of glucose uptake in muscle cells. $\underline{A m ~ J}$ Physiol Endocrinol Metab 280: E229-E237, 2001.

69. Mootha VK, Lindgren CM, Eriksson KF, Subramanian A, Sihag S, Lehar J, Puigserver P, Carlsson E, Ridderstrale M, Laurila E, Houstis N, Daly MJ, Patterson N, Mesirov JP, Golub TR, Tamayo P, Spiegelman B, Lander ES, Hirschhorn JN, Altshuler D, and Groop LC. PGC-1alpharesponsive genes involved in oxidative phosphorylation are coordinately downregulated in human diabetes. $\underline{\mathrm{Nat}}$ Genet 34: 267-273, 2003.

70. Murphy MP. How mitochondria produce reactive oxygen species. Biochem J 17: 1-13, 2009.

71. Nakae J, Oki M, and Cao Y. The FoxO transcription factors and metabolic regulation. FEBS Lett 582: 54-67, 2008.

72. Ni HM, Williams JA, and Ding WX. Mitochondrial dynamics and mitochondrial quality control. Redox Biol 4C: 6-13, 2014.

73. Niemann B, Chen Y, Teschner M, Li L, Silber RE, and Rohrbach S. Obesity induces signs of premature cardiac aging in younger patients: the role of mitochondria. $\mathrm{J} \mathrm{Am}$ Coll Cardiol 57: 577-585, 2011.

74. Nisoli E, Tonello C, Cardile A, Cozzi V, Bracale R, Tedesco L, Falcone S, Valerio A, Cantoni O, Clementi E, Moncada S, and Carruba MO. Calorie restriction promotes mitochondrial biogenesis by inducing the expression of eNOS. Science 310: 314-317, 2005.

75. Noland RC, Koves TR, Seiler SE, Lum H, Lust RM, Ilkayeva O, Stevens RD, Hegardt FG, and Muoio DM. Carnitine insufficiency caused by aging and overnutrition compromises mitochondrial performance and metabolic control. J Biol Chem 284: 22840-22852, 2009.

76. Ojuka EO. Role of calcium and AMP kinase in the regulation of mitochondrial biogenesis and GLUT4 levels in muscle. Proc Nutr Soc 63: 275-278, 2004.

77. Pan DA, Lillioja S, Kriketos AD, Milner MR, Baur LA, Bogardus C, Jenkins AB, and Storlien LH. Skeletal muscle triglyceride levels are inversely related to insulin action. Diabetes 46: 983-988, 1997.

78. Patti ME, Butte AJ, Crunkhorn S, Cusi K, Berria R, Kashyap S, Miyazaki Y, Kohane I, Costello M, Saccone R, Landaker EJ, Goldfine AB, Mun E, DeFronzo R, Finlayson J, Kahn CR, and Mandarino LJ. Coordinated reduction of genes of oxidative metabolism in humans with insulin resistance and diabetes: potential role of PGC1 and NRF1. Proc Natl Acad Sci U S A 100: 84668471, 2003.

79. Perseghin G, De Cobelli F, Esposito A, Belloni E, Lattuada G, Canu T, Invernizzi PL, Ragogna F, La Torre A, Scifo P, Alberti G, Del Maschio A, and Luzi L. Left ventricular function and energy metabolism in middle-aged men 
undergoing long-lasting sustained aerobic oxidative training. Heart 95: 630-635, 2009.

80. Petersen KF, Dufour S, Befroy D, Garcia R, and Shulman GI. Impaired mitochondrial activity in the insulin-resistant offspring of patients with type 2 diabetes. $\underline{N \text { Engl J Med }}$ 350: 664-671, 2004.

81. Phielix E, Meex R, Ouwens DM, Sparks L, Hoeks J, Schaart G, Moonen-Kornips E, Hesselink MK, and Schrauwen P. High oxidative capacity due to chronic exercise training attenuates lipid-induced insulin resistance. Diabetes 61: 2472-2478, 2012.

82. Phielix E, Schrauwen-Hinderling VB, Mensink M, Lenaers E, Meex R, Hoeks J, Kooi ME, Moonen-Kornips E, Sels JP, Hesselink MK, and Schrauwen P. Lower intrinsic ADP-stimulated mitochondrial respiration underlies in vivo mitochondrial dysfunction in muscle of male type 2 diabetic patients. Diabetes 57: 2943-2949, 2008.

83. Quistorff B, Johansen L, and Sahlin K. Absence of phosphocreatine resynthesis in human calf muscle during ischaemic recovery. Biochem J 291 (Pt 3): 681-686, 1993.

84. Rodgers JT, Lerin C, Haas W, Gygi SP, Spiegelman BM, and Puigserver P. Nutrient control of glucose homeostasis through a complex of PGC-1alpha and SIRT1. Nature 434: 113-118, 2005.

85. Salpea KD, Talmud PJ, Cooper JA, Maubaret CG, Stephens JW, Abelak K, and Humphries SE. Association of telomere length with type 2 diabetes, oxidative stress and UCP2 gene variation. Atherosclerosis 209: 42-50, 2010.

86. Scheibye-Knudsen M, Fang EF, Croteau DL, Wilson DM, 3rd, and Bohr VA. Protecting the mitochondrial powerhouse. Trends Cell Biol 25: 158-170, 2015.

87. Scheuermann-Freestone M, Madsen PL, Manners D, Blamire AM, Buckingham RE, Styles P, Radda GK, Neubauer S, and Clarke K. Abnormal cardiac and skeletal muscle energy metabolism in patients with type 2 diabetes. Circulation 107: 3040-3046, 2003.

87a. Schilling JD. The mitochondria in diabetic heart failure: From pathogenesis to therapeutic promise. Antioxid Redox Signal 22: 1515-1526, 2015.

88. Schmid AI, Schrauwen-Hinderling VB, Andreas M, Wolzt M, Moser E, and Roden M. Comparison of measuring energy metabolism by different (31) P-magnetic resonance spectroscopy techniques in resting, ischemic, and exercising muscle. Magn Reson Med 67: 898-905, 2012.

89. Schrauwen P and Hesselink MK. Oxidative capacity, lipotoxicity, and mitochondrial damage in type 2 diabetes. Diabetes 53: 1412-1417, 2004.

90. Schrauwen P and Timmers S. Can resveratrol help to maintain metabolic health? Proc Nutr Soc 73: 271-277, 2014.

91. Schrauwen-Hinderling VB, Hesselink MK, Meex R, van der Made S, Schar M, Lamb H, Wildberger JE, Glatz J, Snoep G, Kooi ME, and Schrauwen P. Improved ejection fraction after exercise training in obesity is accompanied by reduced cardiac lipid content. J Clin Endocrinol Metab 95: 1932-1938, 2010.

92. Schrauwen-Hinderling VB, Kooi ME, Hesselink MK, Jeneson JA, Backes WH, van Echteld CJ, van Engelshoven JM, Mensink M, and Schrauwen P. Impaired in vivo mitochondrial function but similar intramyocellular lipid content in patients with type 2 diabetes mellitus and BMImatched control subjects. Diabetologia 50: 113-120, 2007.

93. Schrauwen-Hinderling VB, Meex RC, Hesselink MK, van de Weijer T, Leiner T, Schar M, Lamb HJ, Wildberger JE, Glatz JF, Schrauwen P, and Kooi ME. Cardiac lipid content is unresponsive to a physical activity training intervention in type 2 diabetic patients, despite improved ejection fraction. Cardiovasc Diabetol 10: 47, 2011.

94. Schroeder MA, Lau AZ, Chen AP, Gu Y, Nagendran J, Barry J, Hu X, Dyck JR, Tyler DJ, Clarke K, Connelly $\mathrm{KA}$, Wright GA, and Cunningham $\mathrm{CH}$. Hyperpolarized (13) C magnetic resonance reveals early- and late-onset changes to in vivo pyruvate metabolism in the failing heart. Eur J Heart Fail 15: 130-140, 2013.

95. Shinmura K, Tamaki K, Sano M, Murata M, Yamakawa $\mathrm{H}$, Ishida $\mathrm{H}$, and Fukuda K. Impact of long-term caloric restriction on cardiac senescence: caloric restriction ameliorates cardiac diastolic dysfunction associated with aging. J Mol Cell Cardiol 50: 117-127, 2011.

96. Shinmura K, Tamaki K, Sano M, Nakashima-Kamimura N, Wolf AM, Amo T, Ohta S, Katsumata Y, Fukuda K, Ishiwata K, Suematsu M, and Adachi T. Caloric restriction primes mitochondria for ischemic stress by deacetylating specific mitochondrial proteins of the electron transport chain. Circ Res 109: 396-406, 2011.

96a. Sung MM, Hamza SM, and Dyck JRB. Myocardial Metabolism in Diabetic Cardiomyopathy: Potential Therapeutic Targets. Antioxid Redox Signal 22: 1606-1630, 2015.

97. Takahashi H, Inaki M, Fujimoto K, Katsuta S, Anno I, Niitsu M, and Itai Y. Control of the rate of phosphocreatine resynthesis after exercise in trained and untrained human quadriceps muscles. Eur J Appl Physiol 71: 396-404, 1995.

98. Timmers S, Konings E, Bilet L, Houtkooper RH, van de Weijer T, Goossens GH, Hoeks J, van der Krieken S, Ryu D, Kersten S, Moonen-Kornips E, Hesselink MK, Kunz I, Schrauwen-Hinderling VB, Blaak EE, Auwerx J, and Schrauwen P. Calorie restriction-like effects of 30 days of resveratrol supplementation on energy metabolism and metabolic profile in obese humans. Cell Metab 14: 612$622,2011$.

99. Tocchetti CG, Caceres V, Stanley BA, Xie C, Shi S, Watson WH, O'Rourke B, Spadari-Bratfisch RC, Cortassa S, Akar FG, Paolocci N, and Aon MA. GSH or palmitate preserves mitochondrial energetic/redox balance, preventing mechanical dysfunction in metabolically challenged myocytes/hearts from type 2 diabetic mice. Diabetes 61: 3094-3105, 2012.

100. Toledo FG, Menshikova EV, Ritov VB, Azuma K, Radikova Z, DeLany J, and Kelley DE. Effects of physical activity and weight loss on skeletal muscle mitochondria and relationship with glucose control in type 2 diabetes. Diabetes 56: 2142-2147, 2007.

101. van Tienen FH, Praet SF, de Feyter HM, van den Broek NM, Lindsey PJ, Schoonderwoerd KG, de Coo IF, Nicolay K, Prompers JJ, Smeets HJ, and van Loon LJ. Physical activity is the key determinant of skeletal muscle mitochondrial function in type 2 diabetes. $\underline{J \text { Clin Endocrinol }}$ Metab 97: 3261-3269, 2012.

102. Vettor R, Valerio A, Ragni M, Trevellin E, Granzotto M, Olivieri M, Tedesco L, Ruocco C, Fossati A, Fabris R, Serra R, Carruba MO, and Nisoli E. Exercise training boosts eNOS-dependent mitochondrial biogenesis in mouse heart: role in adaptation of glucose metabolism. $\underline{\mathrm{Am}}$ J Physiol Endocrinol Metab 306: E519-E528, 2014.

103. Wang W, Wang Y, Long J, Wang J, Haudek SB, Overbeek P, Chang BH, Schumacker PT, and Danesh FR. Mitochondrial fission triggered by hyperglycemia is mediated by ROCK1 activation in podocytes and endothelial cells. Cell Metab 15: 186-200, 2012. 
104. Wohlgemuth SE, Seo AY, Marzetti E, Lees HA, and Leeuwenburgh C. Skeletal muscle autophagy and apoptosis during aging: effects of calorie restriction and lifelong exercise. Exp Gerontol 45: 138-148, 2010.

105. Yoshino J, Conte C, Fontana L, Mittendorfer B, Imai S, Schechtman KB, Gu C, Kunz I, Rossi Fanelli F, Patterson BW, and Klein S. Resveratrol supplementation does not improve metabolic function in nonobese women with normal glucose tolerance. Cell Metab 16: 658-664, 2012.

\section{Address correspondence to: \\ Prof. Patrick Schrauwen Department of Human Biology Maastricht University Medical Center PO Box 616 \\ Maastricht 6200 MD \\ The Netherlands}

E-mail: p.schrauwen@maastrichtuniversity.nl

Date of first submission to ARS Central, March 8, 2015; date of acceptance, March 14, 2015.

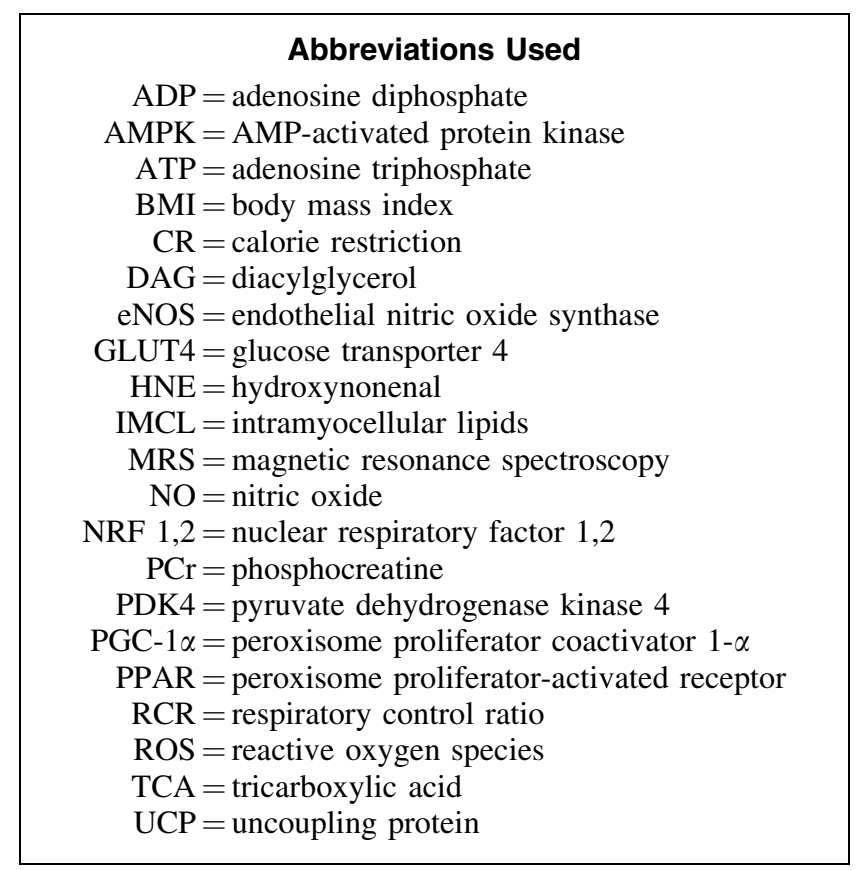




\section{This article has been cited by:}

1. Miguel A. Aon, Sonia Cortassa, Magdalena Juhaszova, José A. González-Reyes, Miguel Calvo-Rubio, José M. Villalba, Andrew D. Lachance, Bruce D. Ziman, Sarah J. Mitchell, Kelsey N. Murt, Jessie E. C. Axsom, Irene Alfaras, Steven L. Britton, Lauren G. Koch, Rafael de Cabo, Edward G. Lakatta, Steven J. Sollott. 2021. Mitochondrial health is enhanced in rats with higher vs. lower intrinsic exercise capacity and extended lifespan. npj Aging and Mechanisms of Disease 7:1. . [Crossref]

2. Francesca Battista, Andrea Ermolao, Marleen A. Baak, Kristine Beaulieu, John E. Blundell, Luca Busetto, Eliana V. Carraça, Jorge Encantado, Dror Dicker, Nathalie Farpour-Lambert, Adriyan Pramono, Alice Bellicha, Jean-Michel Oppert. 2021. Effect of exercise on cardiometabolic health of adults with overweight or obesity: Focus on blood pressure, insulin resistance, and intrahepatic fat-A systematic review and meta-analysis. Obesity Reviews 22:S4. . [Crossref]

3. Khalil Saadeh, Karan R. Chadda, Shiraz Ahmad, Haseeb Valli, Nakulan Nanthakumar, Ibrahim T. Fazmin, Charlotte E. Edling, Christopher L.-H. Huang, Kamalan Jeevaratnam. 2021. Molecular basis of ventricular arrhythmogenicity in a Pgc-1 $\alpha$ deficient murine model. Molecular Genetics and Metabolism Reports 27, 100753. [Crossref]

4. Su-Jeong Kim, Brendan Miller, Hiroshi Kumagai, Ana R. Silverstein, Melanie Flores, Kelvin Yen. 2021. Mitochondrial-derived peptides in aging and age-related diseases. GeroScience 43:3, 1113-1121. [Crossref]

5. Torsak Tippairote, Geir Bjørklund, Augchara Yaovapak. 2021. The continuum of disrupted metabolic tempo, mitochondrial substrate congestion, and metabolic gridlock toward the development of non-communicable diseases. Critical Reviews in Food Science and Nutrition 1-17. [Crossref]

6. Sanjay Kalra, Ambika Gopalakrishnan Unnikrishnan, Manash P Baruah, Rakesh Sahay, Ganapathi Bantwal. 2021. Metabolic and Energy Imbalance in Dysglycemia-Based Chronic Disease. Diabetes, Metabolic Syndrome and Obesity: Targets and Therapy Volume 14, 165-184. [Crossref]

7. Karen Lambert, Marie Demion, Jean-Christophe Lagacé, Marie Hokayem, Mamta Dass, Anne Virsolvy, Bernard Jover, Annick bourret, Catherine Bisbal. 2021. Grape polyphenols and exercise training have distinct molecular effects on cardiac hypertrophy in a model of obese insulin-resistant rats. The Journal of Nutritional Biochemistry 87, 108522. [Crossref]

8. Raghuram Nagarathna, Parul Bali, Akshay Anand, Vinod Srivastava, Suchitra Patil, Guruprasad Sharma, Krishna Manasa, Viraaj Pannu, Amit Singh, Hongasandra R. Nagendra. 2020. Prevalence of Diabetes and Its Determinants in the Young Adults Indian Population-Call for Yoga Intervention. Frontiers in Endocrinology 11. . [Crossref]

9. Fernando Lizcano, Felipe Arroyave. 2020. Control of Adipose Cell Browning and Its Therapeutic Potential. Metabolites 10:11, 471. [Crossref]

10. Mengyuan Ge, Flavia Fontanesi, Sandra Merscher, Alessia Fornoni. 2020. The Vicious Cycle of Renal Lipotoxicity and Mitochondrial Dysfunction. Frontiers in Physiology 11. . [Crossref]

11. Yushu Chen, Wen Zeng, Wei Chen, Yu Zhang, Tong Zhu, Jiayu Sun, Zhigang Liang, Lei Wang, Zunyuan Yang, Bing Wu, Bin Song, Fangtong Wang, Yinan Liang, Li Gong, Jie Zheng, Fabao Gao. 2020. Evaluating the correlation of the impairment between skeletal muscle and heart using MRI in a spontaneous type 2 diabetes mellitus rhesus monkey model. Acta Diabetologica 57:6, 673-679. [Crossref]

12. Larissa Vetter, Sonia Cortassa, Brian O’Rourke, Antonis A. Armoundas, Djahida Bedja, Johann M. E. Jende, Martin Bendszus, Nazareno Paolocci, Steven J. Sollot, Miguel A. Aon, Felix T. Kurz. 2020. Diabetes Increases the Vulnerability of the Cardiac Mitochondrial Network to Criticality. Frontiers in Physiology 11. . [Crossref]

13. Charlotte E. Edling, Ibrahim T. Fazmin, Khalil Saadeh, Karan R. Chadda, Shiraz Ahmad, Haseeb Valli, Christopher L.-H. Huang, Kamalan Jeevaratnam. 2019. Molecular basis of arrhythmic substrate in ageing murine peroxisome proliferator-activated receptor $\gamma$ co-activator deficient hearts modelling mitochondrial dysfunction. Bioscience Reports 39:12. . [Crossref]

14. Carrie V. Breton, Ashley Y. Song, Jialin Xiao, Su-Jeong Kim, Hemal H. Mehta, Junxiang Wan, Kelvin Yen, Constantinos Sioutas, Fred Lurmann, Shanyan Xue, Todd E. Morgan, Junfeng Zhang, Pinchas Cohen. 2019. Effects of air pollution on mitochondrial function, mitochondrial DNA methylation, and mitochondrial peptide expression. Mitochondrion 46, 22-29. [Crossref]

15. Mahdi Vazirian, Seyed Mohammad Nabavi, Samineh Jafari, Azadeh Manayi. 2018. Natural activators of adenosine 5'monophosphate (AMP)-activated protein kinase (AMPK) and their pharmacological activities. Food and Chemical Toxicology 122, 69-79. [Crossref]

16. Reuben L Smith, Maarten R Soeters, Rob C I Wüst, Riekelt H Houtkooper. 2018. Metabolic Flexibility as an Adaptation to Energy Resources and Requirements in Health and Disease. Endocrine Reviews 39:4, 489-517. [Crossref]

17. Eugene Lee, Jin Choi, Hyun Soon Lee. 2017. Palmitate induces mitochondrial superoxide generation and activates AMPK in podocytes. Journal of Cellular Physiology 232:12, 3209-3217. [Crossref] 
18. Christiane Marie Bourgin Folke Gam, Lea Hüche Larsen, Ole Hartvig Mortensen, Line Engelbrechtsen, Steen Seier Poulsen, Klaus Qvortrup, Elisabeth Reinhart Mathiesen, Peter Damm, Bjørn Quistorff. 2017. Unchanged mitochondrial phenotype, but accumulation of lipids in the myometrium in obese pregnant women. The Journal of Physiology 595:23, 7109-7122. [Crossref]

19. Yichi Yu, Lei Wang, Florian Delguste, Arthur Durand, Axel Guilbaud, Clementine Rousselin, Ann Marie Schmidt, Frédéric Tessier, Eric Boulanger, Remi Neviere. 2017. Advanced glycation end products receptor RAGE controls myocardial dysfunction and oxidative stress in high-fat fed mice by sustaining mitochondrial dynamics and autophagy-lysosome pathway. Free Radical Biology and Medicine 112, 397-410. [Crossref]

20. Fan Wu, Baile Wang, Saisai Zhang, Lihua Shi, Yanfang Wang, Rongrong Xiong, Xuebo Pan, Fanghua Gong, Xiaokun Li, Zhuofeng Lin. 2017. FGF21 ameliorates diabetic cardiomyopathy by activating the AMPK-paraoxonase 1 signaling axis in mice. Clinical Science 131:15, 1877-1893. [Crossref]

21. SANNA M. HONKALA, KUMAIL K. MOTIANI, JARI-JOONAS ESKELINEN, ANNA SAVOLAINEN, VIRVA SAUNAVAARA, KIRSI A. VIRTANEN, ELIISA LÖYTTYNIEMI, JUKKA KAPANEN, JUHANI KNUUTI, KARI K. KALLIOKOSKI, JARNA C. HANNUKAINEN. 2017. Exercise Training Reduces Intrathoracic Fat Regardless of Defective Glucose Tolerance. Medicine \& Science in Sports \& Exercise 49:7, 1313-1322. [Crossref]

22. Carrier Alice. 2017. Metabolic Syndrome and Oxidative Stress: A Complex Relationship. Antioxidants \& Redox Signaling 26:9, 429-431. [Abstract] [Full Text] [PDF] [PDF Plus]

23. Elisa Fabbri, Chee W. Chia, Richard G. Spencer, Kenneth W. Fishbein, David A. Reiter, Donnie Cameron, Ariel C. Zane, Zenobia A. Moore, Marta Gonzalez-Freire, Marco Zoli, Stephanie A. Studenski, Rita R. Kalyani, Josephine M. Egan, Luigi Ferrucci. 2017. Insulin Resistance Is Associated With Reduced Mitochondrial Oxidative Capacity Measured by 31 P-Magnetic Resonance Spectroscopy in Participants Without Diabetes From the Baltimore Longitudinal Study of Aging. Diabetes 66:1, 170-176. [Crossref]

24. Miguel A. Aon, Sonia Cortassa, Magdalena Juhaszova, Steven J. Sollott. 2016. Mitochondrial health, the epigenome and healthspan. Clinical Science 130:15, 1285-1305. [Crossref]

25. Xun Wang, Zhihui Feng, Xueqiang Wang, Liang Yang, Shujun Han, Ke Cao, Jie Xu, Lin Zhao, Yong Zhang, Jiankang Liu. 2016. O-GlcNAcase deficiency suppresses skeletal myogenesis and insulin sensitivity in mice through the modulation of mitochondrial homeostasis. Diabetologia 59:6, 1287-1296. [Crossref]

26. Bernd Schöpf, Georg Schäfer, Anja Weber, Heribert Talasz, Iris E. Eder, Helmut Klocker, Erich Gnaiger. 2016. Oxidative phosphorylation and mitochondrial function differ between human prostate tissue and cultured cells. The FEBS Journal 283:11, 2181-2196. [Crossref]

27. Joel T. Haas, Sven Francque, Bart Staels. 2016. Pathophysiology and Mechanisms of Nonalcoholic Fatty Liver Disease. Annual Review of Physiology 78:1, 181-205. [Crossref]

28. Carlo G. Tocchetti, Brian A. Stanley, Vidhya Sivakumaran, Djahida Bedja, Brian O'Rourke, Nazareno Paolocci, Sonia Cortassa, Miguel A. Aon. 2015. Impaired mitochondrial energy supply coupled to increased $\mathrm{H} 2 \mathrm{O} 2$ emission under energy/redox stress leads to myocardial dysfunction during Type I diabetes. Clinical Science 129:7, 561-574. [Crossref] 